Max-Planck-Institut für demografische Forschung Max Planck Institute for Demographic Research Konrad-Zuse-Strasse 1 - D-18057 Rostock - GERMANY

Tel +49 (0) 3812081 - 0; Fax +49 (0) 3812081 - 202;

http://www.demogr.mpg.de

MPIDR WORKING PAPER WP 2004-019

JUNE 2004

Gendering the Family Composition:

Sex Preferences for Children

and Childbearing Behavior in the

Nordic Countries

Gunnar Andersson (andersson@ demogr.mpg.de)

Karsten Hank (hank@mea.uni-mannheim.de)

Marit Rønsen (marit.ronsen@ssb.no)

Andres Vikat (vikat@demogr.mpg.de)

This working paper has been approved for release by: Andres Vikat (vikat@demogr.mpg.de)

Deputy Head of the Laboratory of Contemporary European Fertility and Family Dynamics.

(C) Copyright is held by the authors.

Working papers of the Max Planck Institute for Demographic Research receive only limited review. Views or opinions expressed in working papers are attributable to the authors and do not necessarily reflect those of the Institute. 


\title{
Gendering the Family Composition: Sex Preferences for Children and Childbearing Behavior in the Nordic Countries
}

\author{
Gunnar Andersson ${ }^{a}$, Karsten Hank ${ }^{b}$, Marit Rønsen $^{c}$, and Andres Vikat ${ }^{a}$
}

June 3, 2004

\begin{abstract}
It has been argued recently that a society's 'gender system' influences parents' sex preferences for children. If this was true, one should expect to find no evidence of such preferences in countries with a high level of gender equality. In this paper we exploit population register data from Denmark, Finland, Norway, and Sweden to examine continuities and changes in parental sex preferences in the Nordic countries during the last three to four decades. First, we cannot observe a visible effect of the sex of the first-born child on second birth risks. Secondly, we detect a distinct preference for at least one child of each sex among parents of two children. Next to this combination preference our analysis reveals, thirdly, that Danish, Norwegian and Swedish parents developed a preference for having a daughter, while Finns exhibit a significant son preference. These findings show that modernization and more equal opportunities for women and men do not necessarily lead to parental gender indifference. On the contrary, they might even result in 'new' sex preferences.
\end{abstract}

\footnotetext{
${ }^{a}$ Max Planck Institute for Demographic Research, Konrad-Zuse-Str. 1, D-18057 Rostock, Germany. Email: andersson@ demogr.mpg.de; vikat@ demogr.mpg.de.

${ }^{\mathrm{b}}$ Mannheim Research Institute for the Economics of Aging, University of Mannheim, Building L 13, 17, D-68131 Mannheim, Germany. Phone: +49-621-181-3439. Fax: +49-621-181-1863. Email: hank@mea.uni-mannheim.de.

${ }^{c}$ Division for Social and Demographic Research, Statistics Norway, P.O. Box 8131 Dep, N0033 Oslo, Norway. Email: marit.ronsen@ssb.no.
} 


\section{Background}

Sex preferences for children have been a prominent issue in demographic work on developing countries for a long time (e.g., Arnold 1997; Basu and Das Gupta 2001; Cleland et al. 1983). ${ }^{1}$ However, we also detect a growing interest in the topic in recent publications on western societies. While this has some tradition in the US, it is a fairly new phenomenon in European research (e.g., Hank and Kohler 2000; Marleau and Saucier 2002). Although various attempts have been made to shed light on the mechanisms underlying the observed patterns of sex preferences for children in industrialized nations (e.g. the value-of-children approach, the modernization hypothesis, or reference to the role of culture), a fully satisfying theoretical explanation is still not at hand (cf. Hank and Kohler 2003: Section II).

The literature on American parents' sex preferences and on the possible impact of the sex composition of children on demographic behavior reaches back to the 1960s and beyond (e.g., Freedman et al. 1960; Williamson 1976). Latest research by Lundberg and Rose (2003), for example, has shown that in the US, the birth of a son may speed up the transition into marriage more than the birth of a daughter when the child is born out-ofwedlock, while there is no significant effect of children's sex on the mother's remarriage probabilities when they are born within a previous marriage. In their study of marital dissolution, Morgan et al. (1988) found that US couples with daughters have had higher risks of separation (see also Katzev et al. 1994). A modest effect of having

\footnotetext{
${ }^{1}$ Next to the desire for a balanced number of sons and daughters, son preference has sometimes been observed, particularly in South Asia. A prominent example for this is India, where the role of parental sex preferences in children's nutrition and medical treatment (e.g., Pande 2003), in child mortality (e.g., Arnold et al. 1998), or in reproductive behavior (e.g., Clark 2000) has been investigated extensively.
} 
daughters versus sons could be detected in the 1960s and 1970s, but it attenuated in subsequent time periods (Morgan and Pollard 2002).

This is consistent with a recent study by Pollard and Morgan (2002) on the sex composition of previous offspring and third births in the US. They argue that changes in the society's gender system have lead to a decreasing effect of children's sex on parents' fertility decisions. In contrast to the longstanding and well-documented observation that US parents with two children of the same sex are more likely to experience a third birth than those with one son and one daughter (e.g., Sloane and Lee 1983; Yamaguchi and Ferguson 1995; see also Dahl and Moretti 2004), the authors claim to have detected a significant decline in the pro-natalist effect of the sex of preceding children after 1985. Pollard and Morgan (2002: 611) conclude that "the observed shifts in fertility patterns could reflect the synergy among cohorts that were primed to be gender indifferent by exposure to social attitudes while growing up, and the period when structural and other social factors (collectively referred to as the 'gender system') enabled such behavior."

Mason (1997: 158) defines the gender system as "the socially constructed expectations for male and female behavior [...]. A gender system's expectations prescribe a division of labor and responsibilities between women and men and grant different rights and obligations to them". To investigate whether societal gender systems actually influence sex preferences for children, cross-national comparative research is highly desirable. If Pollard and Morgan (2002) are right in their assertion that more equal opportunities for women and men result in parental gender indifference, one should expect to find little or no sex preferences for children in countries with a high level of equality between men and women, both in terms of institutionalized 
gender stratification and gender roles (Mason 1997: 159). Despite considerable sex segregation in the labor market (e.g. regarding the occupational distribution or participation in full-time versus part-time work), the Nordic societies are considered to be among the most gender equal (e.g., Bergqvist 1999; Hernes 1987).

In a comparative study of 17 European countries with Fertility and Family Surveys in the 1990s, Hank and Kohler $(2000)^{2}$ find no evidence of sex preferences in Norway and Finland, while their results for Sweden suggest that two-child families with an unbalanced sex composition of children tend to have a significant preference for the yet missing sex. However, studies using larger data bases might provide more accurate, and sometimes different, results. Brunborg (1987), for example, compares the proportions of Norwegian mothers having another child by sex of their previous offspring and provides evidence for a combination preference in the period 1950 to 1985, indicated by higher parity progression rates among women with children of only one sex. Kartovaara (1999) shows that Finnish parents of two same-sex children might be more likely to have a third child, as are those with a two-girl offspring compared to those with a two-boy offspring. In accordance with the study by Hank and Kohler (2000), Schullström (1996) confirms that Swedish parents of same-sex children exhibit higher parity progression probabilities than those having both a son and a daughter. Analyzing the propensity of Swedish mothers to enter into and exit from marriage, Andersson and Woldemicael (2001), on the other hand, find only weak to no effects of

\footnotetext{
${ }^{2}$ The authors focused on the transition from the second to the third child. They found no sex preference at all in France, West Germany, and Poland, a preference for a mixed sex composition in Austria, Belgium, East Germany, Hungary, Italy, Latvia, Slovenia, Spain, and Switzerland, and some indication of girl preference in the Czech Republic, Lithuania, and Portugal.
} 
the sex composition of children on these two demographic processes. Finally, Jacobsen et al. (1999) detect a general preference for a balanced composition of sexes in Denmark during the 1980s and early 1990s, with slightly higher fertility rates in twoboy families than in two-girl families, though (see also Biggar et al. 1999).

Since actual behavioral differences are usually rather small, they are difficult to measure accurately with the limited number of observations available in survey data, on which some of the above-mentioned previous research is based. In the present paper, we exploit extensive population register data from Denmark, Finland, Norway, and Sweden to examine the Nordic case more closely and - most importantly - over time. Our largescale data sources allow us to investigate parallel continuities and changes in parental sex preferences with an exceptionally high degree of accuracy. Using an event-history framework and accounting for the sex of previous children, we analyze second and third birth risks from the early 1960s and 1970s through the late 1990s for all Danish, Norwegian, and Swedish mothers as well as for a large sample of Finnish mothers. During this period, the present-day Nordic welfare-state regime - which explicitly promotes gender equality - emerged fully. At the same time, very similar trends in reproductive behavior could be observed in these countries, which share a common Nordic fertility pattern (cf. Andersson 2004; Vikat 2004).

\section{Data and method}

As noted above, the data for our calculations stem from the population register systems of Denmark, Finland, Norway, and Sweden. These systems have a long history of full and reliable coverage of the local populations and their vital events. They have been computerized since the end of the 1960s and are known to be accurate. We have used 
data on live births and the corresponding exposure times of risk for various subgroups of women. These numbers are derived from the longitudinal information on the dates of each recorded birth of all women in Denmark born in 1945 and later, of a ten percent sample of Finnish women born in 1937 or later, and of all women in Norway and Sweden born in 1925 and onwards. Foreign-born women were excluded from the data sets. See Andersson (2004) and Vikat (2004), respectively, for further details on the available childbearing information in these register data.

We focus on period fertility (cf. Ní Bhrolchaín 1992). The data for Denmark cover the years from 1971 to 1996, the Finnish data stretch from 1971 to 1999, while those of Norway and Sweden range from 1961 to 1999 . We present standardized relative risks of second and third births separately for each year of our observation period. In practice, our estimation techniques amount to the estimation of proportionalhazards (intensity-regression) models, which nowadays is a standard tool for the analysis of time-dependent data (cf. Hoem 1993).

Our main explanatory variable is the sex of previous children. In addition, we use the following set of control variables in our analysis: calendar year (in single calendar years), age of mother (ranging from 15 to 44 in seven groups), and years since previous birth (ranging from 0 to 9 in six groups). See Table 1 for descriptive statistics.

[Table 1 about here]

\section{Results}

Table 2 provides a first summary of our results, displaying relative risks of having another child by the sex-composition of previous children for the entire study periods. 
Each single difference between relative risks in that table is significant on a level far below the standard 5-percent threshold. Since our study is based on the entire populations of Danish, Norwegian, and Swedish parents, and a large sample of the respective Finnish population, testing the significance of effects mainly serves the purpose of demonstrating that the data sets are indeed huge. In addition to the summarized results, we depict our findings with greater detail in Figures 1-8.

[Table 2 about here]

We find no marked effect of the first child's sex on a woman's propensity to have a second child in Denmark (Table 2). This holds for any point in time during our 36year observation period (Figure 1). However, there are consistently higher transition rates to parity three (on average by some $20-25$ percent) if a mother has two children of the same sex (Table 2). Furthermore, from 1978 onwards, mothers of two sons exhibit a birth risk that is roughly ten percent higher than that of mothers of two daughters (Figure 2). Thus, our results confirm the combination preference and girl preference of Danish parents reported in Jacobsen et al. (1999), whose analysis, however, covers the years 1980 to 1993 only.

For Finland, our data set is smaller. Therefore, excess birth risks of mothers of a first-born daughter relative to those of a first-born son fluctuate more than in Denmark, ranging from 0.92 in 1997 to 1.10 in 1999, i.e. only two years later. Although there seems to be a tendency for slightly higher transition rates to the second child after the birth of a girl, the general pattern is too irregular as to speak of any evident boy preference (Figure 3). The picture changes and becomes clearer, though, when we turn 
to mothers of two children. Next to a preference for mixed offspring (as indicated by approximately 20-25 percent higher birth risks in case of two same-sex children; Table 2), we find higher probabilities to progress to parity three among mothers with two daughters relative to mothers with two sons in almost every year under consideration (Figure 4; see also Kartovaara 1999). There is no tendency of a change in this pattern during the study period. In a data set based on 'only' 437,000 two-child-mother years, however, differences in excess birth risks may vary quite strongly from one single calendar year to another.

Finally, our regression results for Norway (Figure 5) and Sweden (Figure 7) provide no evidence of any systematic influence of the sex of the first-born child on women's probability to progress to parity two. This finding is stable across the whole period of observation, which in these cases reaches back to 1961. Regarding the transition to the third birth, we find that mothers of two same-sex children in both countries are significantly more likely to continue childbearing than those who have a boy and a girl as their first two children (Table 2). This is similar to what we observed in the other Nordic countries and is also consistent with earlier research on Norway (Brunborg 1987) and Sweden (Schullström 1996). The magnitude of the excess birth risk among those with same-sex previous children is slightly lower in Norway (15-20 percent; Figure 6) than in Sweden (20-25 percent; Figure 8), but the type of excess risk is the same and it remains fairly stable across all four decades under study. Also strikingly similar to our Danish findings is the emergence of a modest divergence in the effect of having two daughters or two sons, respectively, on the probability of having a third child. Starting in early and mid-1980s, our results for both Norway and Sweden 
indicate a higher childbearing risk by nearly ten percent among women with two boys, relative to those having two girls.

[Figures 1-8 about here]

\section{Discussion}

In addition to the notion of a common fertility regime of the Nordic countries, we find in many respects similar patterns of sex preferences for children in Denmark, Finland, Norway, and Sweden, but some striking differences as well.

First, no visible evidence of sex preferences can be detected in the transition to parity two. Although some studies (e.g., Hank and Kohler 2003; Marleau and Saucier 2002) show that sex preferences for first-born children might well exist in western societies, Pollard and Morgan (2002), for example, have argued that behaviorally relevant sex preferences are unlikely to be present at the lowest parities, where the main decision rather tends to be whether or when to get a (next) child. This should be particularly the case in the Nordic societies, where the existence of a fairly strong twochild norm has been suggested, while parents more often opt not to have a third child (see e.g., Berinde 1999). In this context, there may be little room left for the influence of the first child's sex on second-birth propensities. Nevertheless, Table 2 actually reveals a very weak - but still significant - effect of gender preferences already at this first stage of the family building process. This finding could easily be ignored if it were not for the fact that it tends to support the much stronger patterns that we find for the next parity progression. 
Our second result shows a distinct and stable preference for one child of each sex, at least during the last three to four decades of the $20^{\text {th }}$ century. In all four countries under study, the probability of a third birth is up to 25 percent higher if the first and the second child are both girls or both boys. This is the same dominant pattern of parental sex preferences that can be observed across many different social, economic, and cultural contexts, may they be located in developing countries or in highly industrialized nations (e.g., Arnold 1997; Hank and Kohler 2000).

However, our analysis thirdly reveals some noteworthy exceptions and recent developments as well: From the late 1970s onwards, Danish parents of two children increasingly developed a preference for having a daughter, next to their continuing combination preference. This trend was soon followed by Norwegian and Swedish parents in the early and mid-1980s. In all three countries, mothers of two sons have an almost ten percent higher probability to get another child than those having two daughters. ${ }^{3}$ In Finland, on the other hand, we find higher excess birth risks among mothers of two girls, i.e. indication of a son preference, until today. These results stand in clear contrast to the hypothesis that preferences for a child of a specific sex should not be prevalent in societies that are characterized by a high degree of gender equity, like the Nordic ones. Thus, one needs to reconsider the role that - according to the

\footnotetext{
${ }^{3}$ In an analysis of Danish data, Biggar et al. (1999) find indication of biologic heterogeneity in the likelihood of having male children. They observe that a growing number of prior boys in the family increases a couple's probability of having another son, if getting a next child at all. A similar finding has also been observed for Norway by Brunborg (1987). Although this effect which is likely to be a biologic phenomenon - is very small, girl preference might therefore even result in an increasing male-to-female sex ratio!
} 
argument put forward by Pollard and Morgan (2002) - the societal gender system might play in the formation of sex preferences for children.

Obviously, modernization and increasing gender equality do not necessarily bring about parental gender indifference. On the contrary, they might even result in 'new' sex preferences. $^{4}$ If women would clearly favor girls over boys, a stronger position of women in society and family could indeed lead to a higher 'demand' for female offspring. However, although it is frequently proposed that fathers have a pronounced desire for sons (e.g., Dahl and Moretti 2004), the empirical evidence of sex specific parental preferences for sons or daughters is not always clear (e.g., Hank and Kohler 2003). A peculiar finding reported in Marleau and Saucier (2002) is that first-time pregnant women seem to have developed a preference for having a girl, while nonpregnant women continue to favor a boy as their first-born child. Brockmann (2001), who claims to have detected a preference for girls as first born children in the former German Democratic Republic, follows a different line of argumentation. She contends that a "service-heavy and status-equalizing welfare system, which focused on children and the working population, allowed for a high level of female labor-force participation. It placed the elderly population at a disadvantage, and it attached a positive significance to a female child. [...] What can be predicted at this point is [...] that increasing female

\footnotetext{
${ }^{4}$ Nevertheless, modern sex-selection technologies, sex-selective abortions, or other means of this kind, explicitly designed to influence the sex composition of a couple's offspring, do not play any significant role in western societies. See Mason and Bennet (1977) for an early article on the potential effect of sex-selection technologies on the population sex ratio and Goodkind (1999) for a recent discussion of ethical questions concerning prenatal sex selection. Pebley and Westoff (1982) conclude from their research that there would be only a small overall effect on women's reproductive behaviour, if sex-selection technologies were more readily available in a low-fertility society such as the US.
} 
labor-force participation and the growing 'burden of aging' should increase the value of a daughter, since she assumes both the role of a breadwinner and that of a caregiver." (Brockmann 2001: 199)

While this might lend itself to explain the observed sex preferences in Denmark, Norway, and Sweden, it does not work for Finland. But what makes Finnish parents so different from their Nordic neighbors? We speculate that some traditional values attached to children might perhaps be more prevalent in Finland than elsewhere, as it industrialized later and faster than practically any other highly developed European economy. Finland experienced rapid urbanization only in the 1960s, and therefore elements of traditional thinking that attach a higher value to a son as heir and keeper of the family name may have retained a foothold. Gender equal social, political, and reproductive rights need not necessarily affect culturally rooted sex preferences, at least not immediately. It remains an open question whether, in the course of the $21^{\text {st }}$ century, the Finnish society will follow the three other Nordic countries in the development of a preferred female offspring. Whatever the answer may be, at the turn to this century we find no evidence at all that would indicate an emergence of parental gender indifference in the Nordic countries. Further insights into the probably very context-specific meaning of this 'black box' - including such from other social-science disciplines (e.g. psychology; cf. Hammer and McFerran 1988) - are therefore highly desirable.

\section{Acknowledgements}

An earlier version of this paper was presented at the Population Association of America 2004 Annual Meeting in Boston. We are grateful for comments by Jan Hoem and Gerda Neyer. We would also like to thank the Statistical Offices of Denmark, Finland, 
Norway, and Sweden for providing us with the individual-level register data used in this analysis.

\section{References}

Andersson, G. (2004): Childbearing developments in Denmark, Norway, and Sweden from the 1970s to the 1990s: A comparison. Demographic Research [Online], Special Collection 3 (7), available at http://www.demographic-research.org.

Andersson, G., G. Woldemicael (2001): Sex composition of children as a determinant of marriage disruption and marriage formation: Evidence from Swedish register data. Journal of Population Research, 18 (1), 143-153.

Arnold, F. (1997): Gender preferences for children. Demographic and Health Surveys Comparative Studies No.23.

Arnold, F., Choe, M.K., T.J. Roy (1998): Son preference, the family-building process and child mortality in India. Population Studies, 52 (3), 301-315.

Basu, A., M. Das Gupta (2001): Family systems and the preferred sex of children. In: N.J. Smelser \& P.B. Baltes (Eds.), International Encyclopedia of the Social \& Behavioral Sciences, Vol. 8. Amsterdam (and others): Elsevier, 5350-5357.

Bergqvist, C. (Ed.-in-Chief) (1999): Equal Democracies? Gender and Politics in the Nordic Countries. Oslo: Scandinavian University Press.

Berinde, D. (1999): Pathways to a third child in Sweden. European Journal of Population, 15 (4), 349-378.

Biggar, R.J., J. Wohlfahrt, T. Westergaard, M. Melbye (1999): Sex ratios, family size, and birth order. American Journal of Epidemiology, 150 (9), 957-962.

Brockmann, H. (2001): Girls preferred? Changing patterns of sex preferences in the two German states. European Sociological Review, 17 (2), 189-202.

Brunborg, H. (1987): Gutt eller jente? Tidsskrift for den Norske Lageforening, 14, 1207-1209 
Clark, S. (2000): Son preference and sex composition of children: Evidence from India. Demography, 37 (1), 95-108.

Cleland, J., J. Verrall, M. Vaessen (1983): Preferences for the sex of children and their influence on reproductive behavior. World Fertility Surveys Comparative Studies No.27.

Dahl, G.B., E. Moretti (2004): The demand for sons: Evidence from divorce, fertility, and shotgun marriage. NBER Working Paper 10281, Cambridge, MA.

Freedman, D., R. Freedman, P.K. Whelpton (1960): Size of family and preference for children of each sex. American Journal of Sociology, 66 (2), 141-146.

Goodkind, D. (1999): Should prenatal sex selection be restricted? Ethical questions and their implications for research and policy. Population Studies, 53 (1), 49-61.

Hammer, M., J. McFerran (1988): Preference for sex of child: a research update. Individual Psychology, 44 (4), 481-491.

Hank, K., H.-P. Kohler (2000): Gender preferences for children in Europe: Empirical results from 17 FFS countries. Demographic Research [Online], 2 (1), available at http://www.demographic-research.org/Volumes/Vol2/1.

Hank, K., H.-P. Kohler (2003): Sex preferences for children revisited: New evidence from Germany. Population (English Edition), 58 (1), 133-144.

Hernes, H. (1987): Welfare State and Women Power. Oslo: Norwegian University Press.

Hoem, J.M. (1993): Classical demographic methods of analysis and modern eventhistory techniques. IUSSP: 22nd International Population Conference, Montreal, Canada, Volume 3: 281-291.

Jacobsen, R., H. Møller, G. Engholm (1999): Fertility rates in Denmark in relation to the sexes of preceding children in the family. Human Reproduction, 14 (4), $1127-$ 1130.

Kartovaara, L. (1999): Boy or girl? Does it matter and is it a coincidence or destiny? Paper presented at the European Population Conference, The Hague, Netherlands. 
Katzev, A.R., R.L. Warner, A.C. Acock (1994): Girls or boys? Relationship of child gender to marital instability. Journal of Marriage and the Family, 56 (1), 89-100.

Lundberg, S., E. Rose (2003): Child gender and the transition to marriage. Demography, 40 (2), 333-349.

Marleau, J.D., J.-F. Saucier (2002): Preference for a first-born boy in western societies. Journal of Biosocial Science, 34 (1), 13-27.

Mason, A., N.G. Bennet (1977): Sex selection with biased technologies and its effect on the population sex ratio. Demography, 14 (3), 285-296.

Mason, K.O. (1997): Gender and demographic change: What do we know? In: G.W. Jones et al. (Eds.), The Continuing Demographic Transition. Oxford: Clarendon Press, 158-182.

Morgan, S.P., D. Lye, G. Condron (1988): Sons, daughters and the risk of marital disruption. American Journal of Sociology, 94 (1), 110-129.

Morgan, S.P., M.S. Pollard (2002): Do parents of girls really have a higher risk of divorce? Paper presented at the 2002 Annual Meeting of the Population Association of America, Atlanta.

Ní Bhrolchaín, M. (1992): Period paramount? A critique of the cohort approach to fertility. Population and Development Review, 18 (4), 599-629.

Pande, R. (2003): Selective gender differences in childhood nutrition and immunization in rural India: The role of siblings. Demography, 40 (3), 395-418.

Pebley, A.R., C.F. Westoff (1982): Women's sex preferences in the United States: 1970 to 1975. Demography, 19 (2), 177-189.

Pollard, M.S., S.P. Morgan (2002): Emerging parental gender indifference? Sex composition of children and the third birth. American Sociological Review, 67 (4), 600-613.

Schullström, Y. (1996): Garcon ou fille? Les préférences pour le sexe des enfants dans les générations suédoises 1946-1975. Population, 51 (6), 1243-1245.

Sloane, D.M., C.-F. Lee (1983): Sex of previous children and intentions for further births in the United States, 1965-1976. Demography, 20 (3), 353-367. 
Vikat, A. (2004): Women's labor force attachment and childbearing in Finland. Demographic Research [Online], Special Collection 3 (8), available at http://www.demographic-research.org.

Williamson, N.E. (1976): Sons or Daughters: A Cross-Cultural Survey of Parental Preferences. Beverly Hills, CA: Sage.

Yamaguchi, K., L.R. Ferguson (1995): The stopping and spacing of childbirths and their birth-history predictors: rational-choice theory and event-history analysis. American Sociological Review, 60 (2), 272-298. 


\section{Tables \& Figures}

Table 1: Descriptive statistics - Denmark, Finland, Norway, and Sweden

\begin{tabular}{|l|r|r|r|r|}
\hline & $\begin{array}{c}\text { Woman-years as } \\
\text { one-child mother }\end{array}$ & $\begin{array}{c}\text { Number of } \\
\text { second births }\end{array}$ & $\begin{array}{c}\text { Woman-years as } \\
\text { two-child mother }\end{array}$ & $\begin{array}{c}\text { Number of } \\
\text { third births }\end{array}$ \\
\hline Denmark & $2,955,900$ & 479,800 & $3,421,700$ & 138,700 \\
\hline Finland & 373,800 & 57,000 & 436,900 & 22,100 \\
\hline Norway & $4,690,300$ & 744,800 & $5,441,600$ & 352,200 \\
\hline Sweden & $7,001,400$ & $1,223,900$ & $9,297,500$ & 470,500 \\
\hline
\end{tabular}

Source: Nordic population registers, authors' calculations.

Table 2: Relative risk of giving birth to another child for one- and two-child mothers, respectively, in Denmark, Finland, Norway, and Sweden

\begin{tabular}{|l|c|c|c|c|}
\hline & Denmark & Finland & Norway & Sweden \\
\hline Second-birth risks of mothers of: & & & & \\
\hline - one girl & 1 & 1 & 1 & 1 \\
\hline - one boy & 1.01 & 0.98 & 1.01 & 1.01 \\
\hline Third-birth risks of mothers of: & & & & \\
\hline - one boy and one girl & 1 & 1 & 1 & 1 \\
\hline - two girls & 1.17 & 1.28 & 1.17 & 1.20 \\
\hline - two boys & 1.27 & 1.17 & 1.20 & 1.25 \\
\hline
\end{tabular}

Source: Nordic population registers, authors' calculations. Results are standardized for calendar year, age of mother, and time since previous birth. 
Figure 1: Second-birth risks of Danish women by sex of the first child, 1971 to 1996 (risks relative to having a boy in 1983).

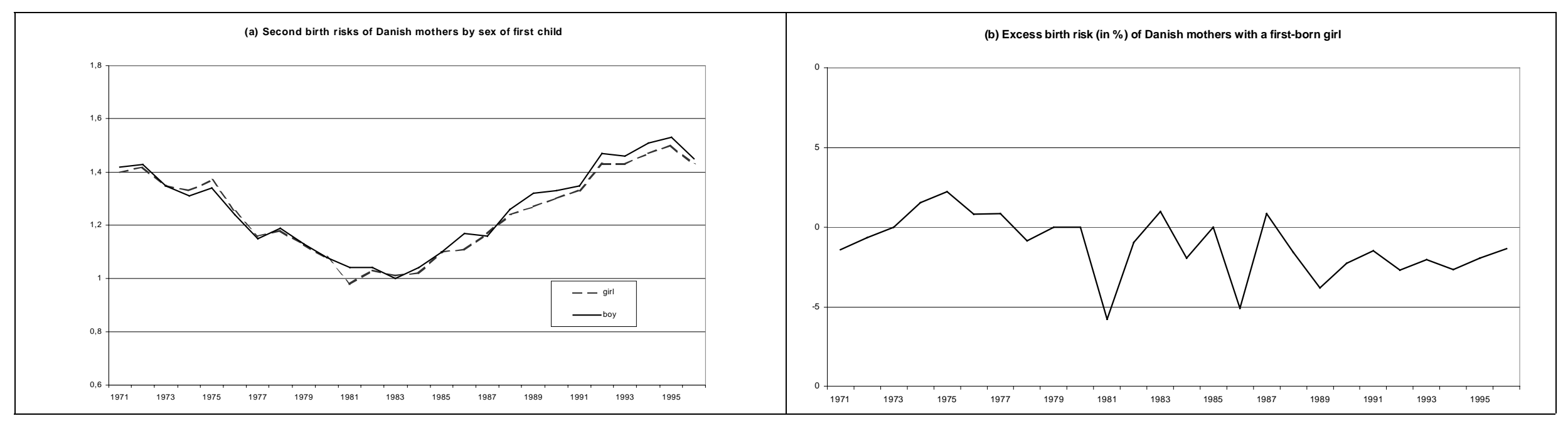

Figure 2: Third-birth risks of Danish women by sex of previous children, 1971 to 1996 (risks relative to having a mixed-sex offspring in 1983).

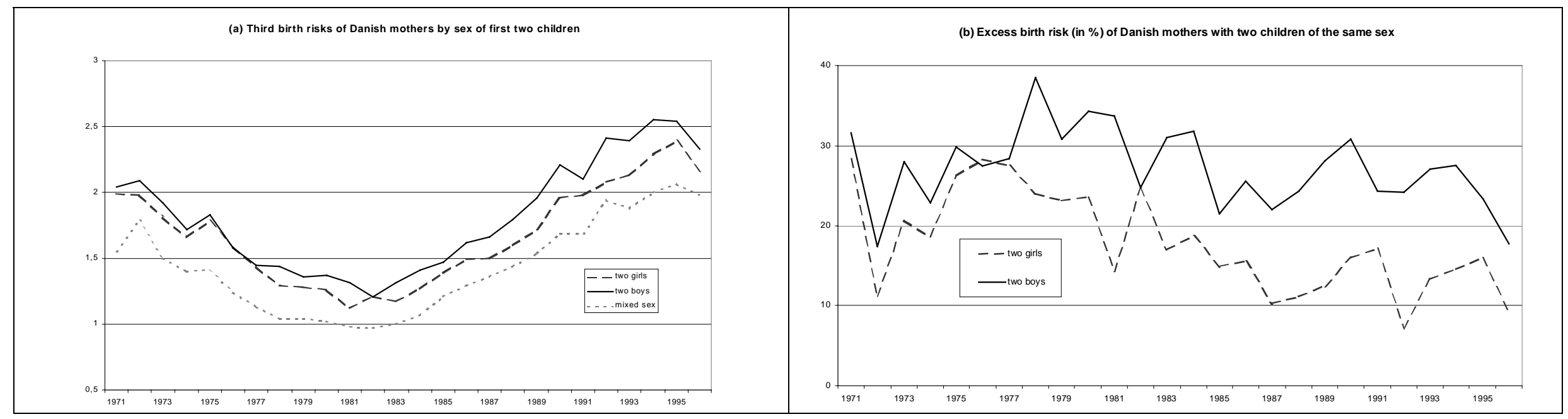

Source: Danish population register, authors' calculations. Results are standardized for age of woman and time since previous birth. 
Figure 3: Second-birth risks of Finnish women by sex of the first child, 1971 to 1999 (risks relative to having a boy in 1983).

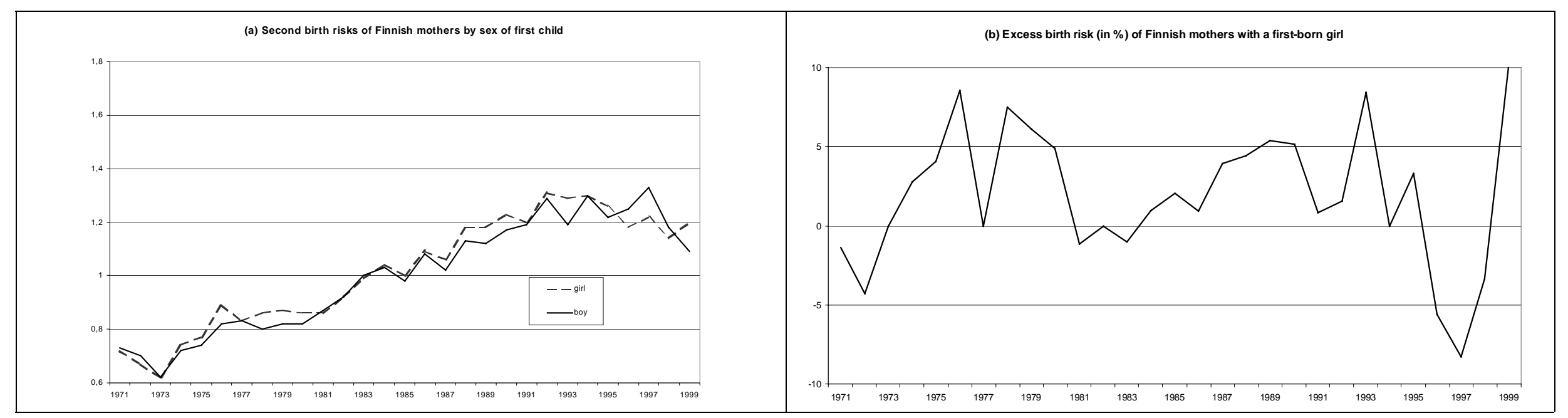

Figure 4: Third-birth risks of Finnish women by sex of previous children, 1971 to 1999 (risks relative to having a mixed-sex offspring in 1983).

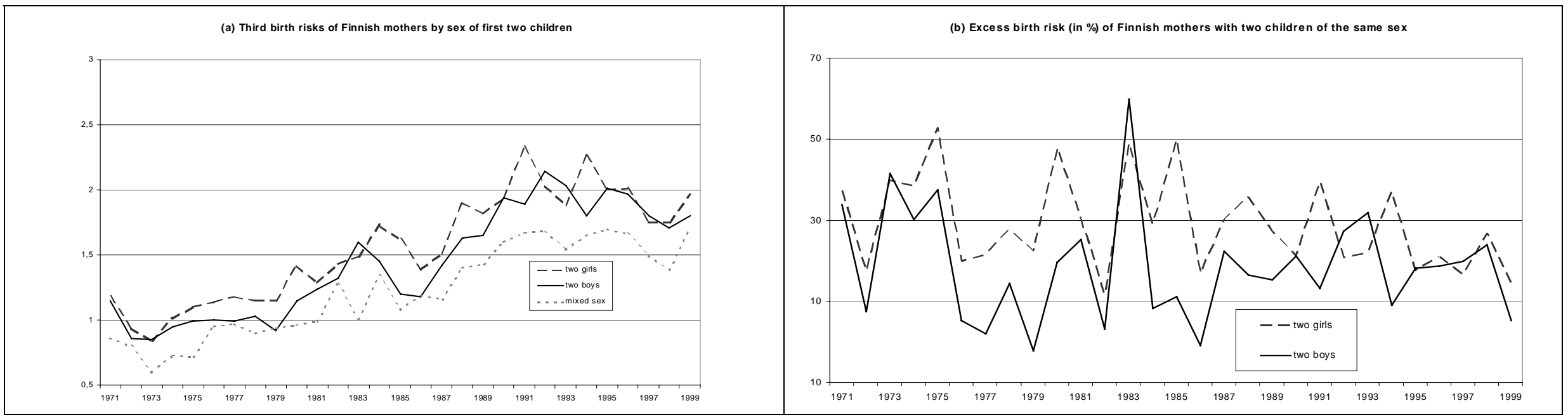

Source: Finnish population register, authors' calculations. Results are standardized for age of woman and time since previous birth. 
Figure 5: Second-birth risks of Norwegian women by sex of the first child, 1961 to 1999 (risks relative to having a boy in 1977).

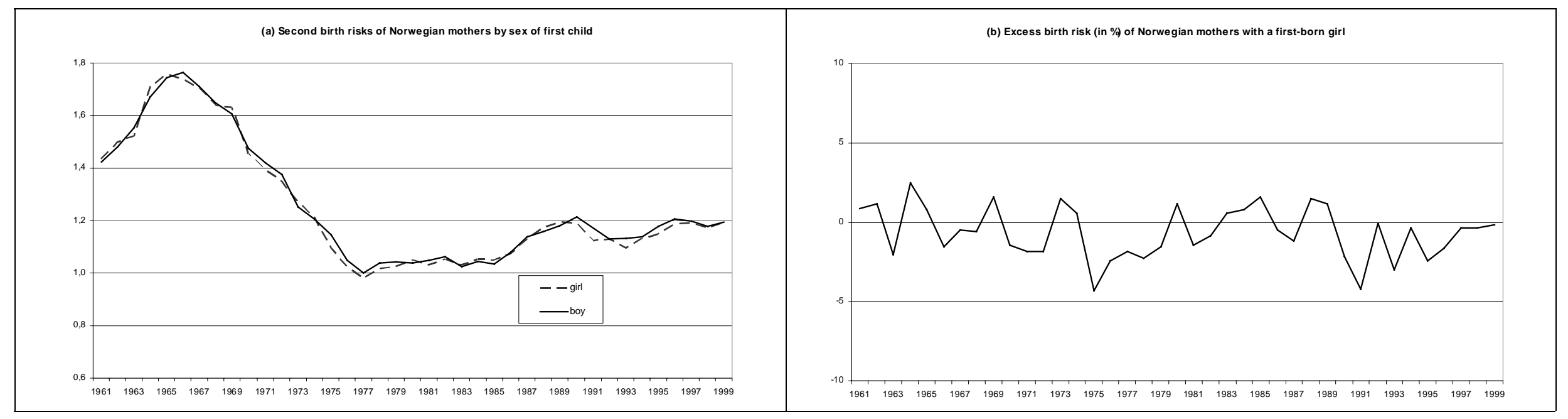

Figure 6: Third-birth risks of Norwegian women by sex of previous children, 1961 to 1999 (risks relative to having a mixed-sex offspring in 1977).

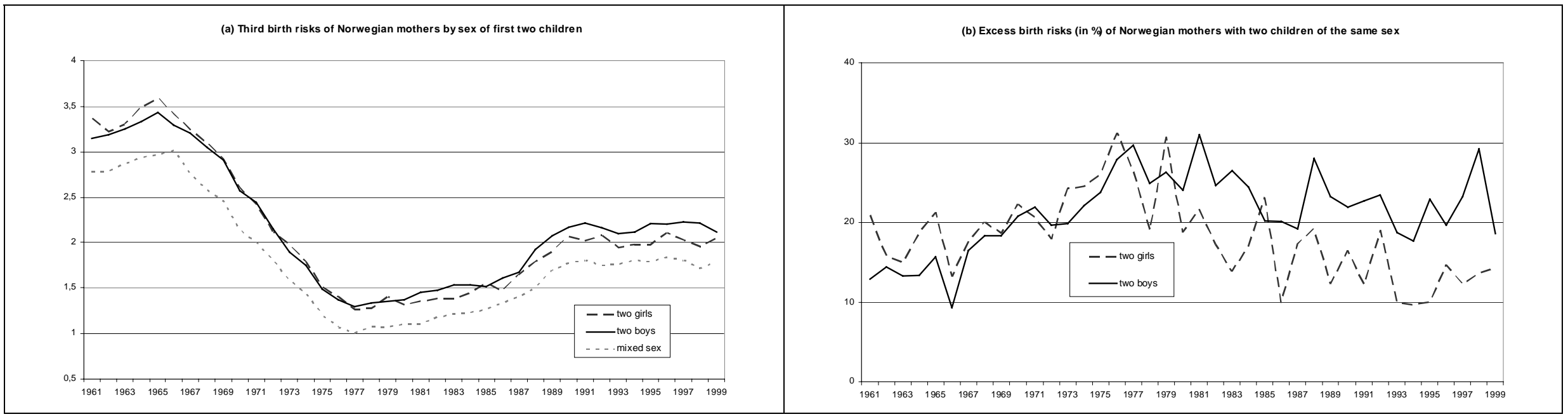

Source: Norwegian population register, authors' calculations. Results are standardized for age of woman and time since previous birth. 
Figure 7: Second-birth risks of Swedish women by sex of the first child, 1961 to 1999 (risks relative to having a boy in 1977).

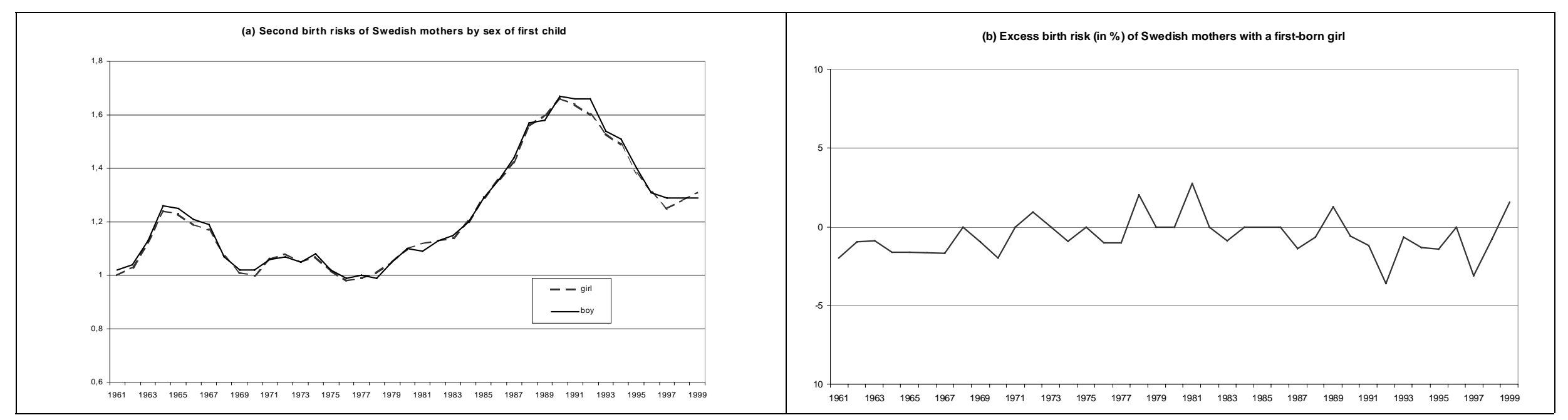

Figure 8: Third-birth risks of Swedish women by sex of previous children, 1961 to 1999 (risks relative to having a mixed-sex offspring in 1977).

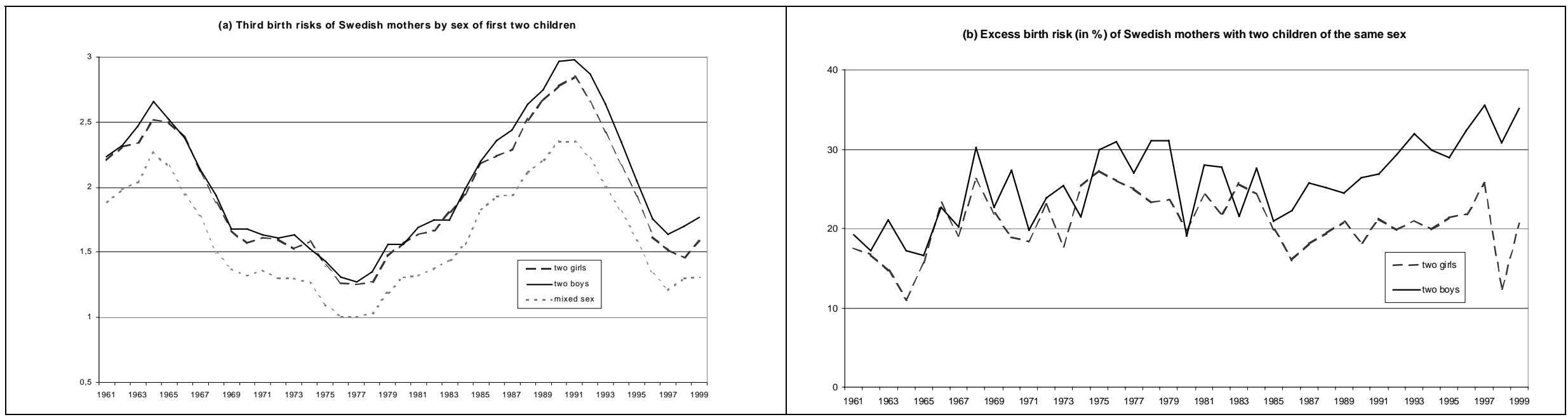

Source: Swedish population register, authors' calculations. Results are standardized for age of woman and time since previous birth. 